\title{
DISCURSO DO PROFESSOR VICENTE RÁO
}

A Congregação da Faculdade de Direito de S. Paulo quer, neste acto publico e solemne, demonstrar o seu alto apreço pelo valor intellectual, moral e civico de um de seus mais illustres membros, o dr. Francisco Morato, conferindolhe, o que pela vez primeira se faz nesta casa, o titulo de prof essor emerito.

Mais do que ao homenageado, a Congregação a si propria honra, pois aqui commemora a figura excepcional de quem, durante mais de vinte annos, continuou com galhardia, em uma de nossas cathedras, as tradições deixadas pelos mais sabios professores, por aquelles, isto é, cuja reputação confunde, com o passado glorioso da Faculdade, o mais glorioso periodo de nossas letras juridicas.

Coube a mim, por escolha de meus doutos collegas, a missão, de que me orgulho, de saudal-o.

Coube a mim, por que, ninguem o ignora, iniciei minha vida profissional e mesmo minha vida publica, sob sua direcção e com elle collaborei, a seguir, durante longos annos.

Nesse convivio, como seu discipulo e companheiro, pude conhecer, dia a dia, hora a hora, todos os aspectos de sua multiforme actividade, sempre dynamica, sempre moça, por que impulsionada, sempre, por fé inquebrantavel naquelles nobres ideaes que conduzem, na batalha incessante da vida, os batalhadores mais bravos e mais destacados.

Outros muitos, delle diriam melhor do que eu.

Mas poucos poderiam, como posso, juntar nesta saudação, a um estricto sentido de justiça, a mais devotada expressão de um prolongado affecto.

Por isso, não venho á tribuna para me desobrigar, protocolarmente, da missão recebida, entremeando de elogios os dados biographicos do illustre mestre. 
Anima-me, ao contrario, a pretensão de esboçar, embora em grandes linhas, a personalidade do primeiro "professor emerito" desta Faculdade, afim de que sua figura fique incisivamente gravada em nosso espirito, em nosso coração, e perpetuada fique, nesta casa, como modelo e guia de todos nós, professores e alumnos.

Muito querer será o meu, nesse proposito de estudar tão eminente personalidade. Mas razão não ha para temôr, quando a causa é bôa e sua bondade suppre as deficiencias de quem a patrocina.

Personalidade multiforme, disse eu. E sempre dynamica. E sempre moça. Assim é, na verdade. Quem quer, porém, que estude sua carreira ininterruptamente ascendente; de logo verificará, na variedade da acção, a persistencia constante e uniforme dos mesmos dons, das mesmas virtudes, o que é dizer, verificará que o todo, tanto quanto cada uma das partes, revela uma só linha central, incisiva, forte, inequivoca, a dominar a estructura harmoniosa e solida de de uma mentalidade pouco commum.

Que é o que nos revela sua vida publica?

- Uma agitação continua, febril, sem repouso, não no paraiso ephemero das accomodações e transigencias, mas só e sempre no terreno da lucta, onde sua figura se ergue dominadora, de viseira alçada e peito descoberto, combatendo tão cavalheirescamente, que os seus proprios adversarios jamais lhe regatearam estima, nem respeito.

Por seu valor e seu renome, se quizesse, poderia ter occupado, na politica e na administração, os mais elevados cargos officiaes.

Mas inutilmente as sereias cantaram aos seus ouvidos, sempre que á seducção do canto se oppunha o dictame da propria consciencia.

Com igual altivez tanto soube recusar, como deixar todas as posições, por fidelidade aos seus ideaes, proceden- 
do sem alarde, sem ostanteção, sem pena, com a singela attitude de quem cumpre, pura e simplesmente, o seu dever.

De que lado o vemos, em seu passado politico?

- Do lado de lá das trincheiras, do lado donde a luta parte e o combate se offerece.

Muito moço, exerceu em Piracicaba, sua cidade natal, o ministerio publico e, ao mesmo tempo, então ligado a convicções monarchicas, fez pela imprensa impávida defesa desse regime.

Ligou-se, mais tarde, á Liga Nacionalista e della foi um emerito propulsor, destacando-se dentro daquelle pugillo de patriotas que, todos, por sua acção, por seu patriotismo sadio e realisador, escreveram uma das mais bellas paginas na historia das lutas civicas brasileiras.

Foi fundador vice-presidente e presidente do Partido Democratico, onde ligou seu nome e sua actuação á actuação e ao nome do Conselheiro Antonio Prado, em memcraveis prélios politicos, de todos conhecidos.

Deputado federal por S. Paulo, de inicio se destacou por seu brilho na tribuna parlamentar, por seus estudos e pareceres no seio das comissões, pelo prestigio e estima grangeados, tão só, á custa de seu proprio valor.

No movimento constitucionalista de 32 , pertenceu á Junta Governativa que aqui se formou e soffreu, como tantos illustres paulistas, prisão e prolongado exilio.

Ora, rememoremos :

- a propaganda monarchica constituia, nos primordios da republica, acto de devotamento a um ideal, a exigir forte coragem civica e accentuando espirito de sacrificio;

- a Liga Nacionalista não era um partido politico, mas uma phalange de prégadores e educadores, que tudo visavam menos a fruição do poder. Do ról de suas actividades, que se destaque e escreva, em linhas de ouro, a campanha em pról do serviço militar obrigatorio!

- o Partido Democratico, partido era, sem duvida, mas de opposição e combate: 
- a deputação federal exercida foi em nome desse partido e, pois, fóra dos quadros governamentaes;

- e que é o que se possa dizer ainda, que já não haja sido dito, da revolução de 32? E da prisão de seus chefes? E de seu exilio? Não era est'outro, sem duvida, um sector de repouso, nem um "jardim de delicias"

De situação mais nitida, mais expressiva do que a sua, não sei. Nem sei de quem delle possa dizer que outra posição occupasse a não ser a da luta e, na luta, outra fileira que não a da vanguarda, a da acção, a do perigo, a da responsabilidade.

Pois apesar disso, ou, talvez, por isso mesmo, gregos e troyannos, adversarios e amigos, sempre lhe prestaram a mais respeitosa homenagem.

Por que? Qual o segredo dessa aureola feliz que o cerca?

Poderia dizer-se, com inteira justiça, que se o dr. Francisco Morato desfructa o respeito de seus proprios adversarios, assim succede por que elle proprio os respeitou, não descendo jamais á deselegancia do personalismo.

Mas seria dizer-se pouco, pois todos nós sabemos quanto são ingratas as lutas politicas, quanta injustiça, quanta perversidade, quantos dissabores envolvem!

Outra razão mais poderosa ha-de existir. Procuremol-a.

Depois da derrota de 32, preso e levado ao Rio de Janeiro, o dr. Francisco Morato alli prestou, na Policia, as suas declarações.

Vamos recordar algumas de suas palavras.

Estas, por exemplo:

"a maior offensa e o mais pungente ultrage que poderia padecer em sua vida, seria de o supporem capaz de sahir da linha de compostura e altivez nos soffrimentos, de faltar á solidariedade para com seus companheiros e conterraneos, de esconder seu devotamento infinito ao seu Estado e de procurar attenuar a sua responsabilidade, nas ho- 
ras afflictivas em que S. Paulo, solitario e desamparado nos sonhos de um grande idealismo, estremece nas amarguras de sua propria grandesa"

Esse, o mais "pungente ultrage" que lhe poderia ter sido feito.

E a graça maior, a unica que pediu, qual foi?

- "a de fazerem recahir sobre sua pessôa, somente sobre sua pessôa, toda a responsabilidade pelo movimento de que participára"

Pagina estoica, disse alguem ao lêl-a.

Pagina de fé, digo eu!

Não desceu jamais ao personalismo. Jamais fugiu á responsabilidade. Estará nisso o segredo que procuramos?

Ainda não.

Respeitar o adversario e ser por elle respeitado, tomar para si as responsabilidades proprias e as alheias, são exteriorisações, simples exteriorisações que necessariamente decorrem de uma formação moral e mental pre-existente.

Nessa formação é que vamos achar o traço caracteristico da personalidade que estudamos.

Que formação é essa, como se originou, como se integrou?

Proclamo e desvendo sem hesitar o segredo que vinha buscando:

- o professor Francisco Morato, homem publico, sempre foi o mesmo professor Francisco Morato jurista, cultor e sacerdote do Direito.

Tanto é dizer que para a tribuna parlamentar, para o scenario politico, para sua actividade civica, elle sempre se conduziu com aquella superioridade de espirito e de attitudes que só a sciencia e a arte do Bem e da Justiça conferem e só conferem aos eleitos.

Antes de tudo, acima de tudo e em tudo, o professor Morato tem sido um jurista, um grande jurista.

Eis a linha mestra de sua personalidade, linha uniforme, linha harmoniosa, linha inconfundivel. 
Vêm-me á memoria as bellas palavras de DupIN, respondendo aos que entendiam não convir ao advogado a vida politica e, principalmente, a vida parlamentar:

"la tribune parlamentaire offre seulement une cause de plus à défendre et la plus belle: celle du pays"

Dessa causa, a causa da Patria, é que o professor Morato tem sido eminente patrono, defendendo-a com escrupulo, competencia, brilho e ardôr inigualaveis.

Por isso affirmei e ora reaffirmo que antes de tudo, acima de tudo, em tudo, o professor Morato tem sido um jurista, um grande jurista.

E falemos um pouco sobre sua vida de advogado.

Por mim, é com redobrado prazer que o faço, pois este aspecto de sua vida desperta em mim as mais gratas recordações.

Fui seu auxiliar de escriptorio, onde comecei a trabalhar como simples dactylographo.

Muito aprendi copiando seus arrazoados, seus pareceres, seus discursos e, mais tarde, já formado, collaborando em seus trabalhos forenses.

Lembro-me perfeitamente: - todas as causas lhe mereciam igual cuidado e escrupulo, fossem grandes, pequenas ou minimas. De sua direcção, jamais escapou o incidente mais banal do processo.

$E^{\prime}$ verdade: - não era um logar de repouso o de seu auxiliar, mas era uma escola inigualavel de ethica e de cultura.

Ouvia os clientes com paciencia inexgotavel e por tal modo se identificava e como que fazia seu o direito sob seu patrocinio, que sua palavra, convicta e confortadora, inspirava, a quem delle se soccorresse, a mais céga confiança. 
E qual outra, se não essa, é a grande missão humana do advogado?

Quero lêr, sobre a nobresa de nossa profissão, bella pagina de Zanardelli:

Eil-a :

"Em contacto diuturno com cada classe social, das mais elevadas ás mais humildes, - todas as realidades da vida se nos offerecem, tenazmente cobertas de trevas, umas, muitas vezes nu'as e sem véo, outras

Por isso, todos os segredos, todos os mysterios da vida social, todos os aspectos multiformes das vicissitudes humanas, em suas grandesas e em suas miserias, todas as harmonias e todas as deformidades de nossa naturesa, tudo, tudo, o impulso irresistivel do interesse pessoal desvenda aos nossos olhos.

Esse estudo do coração humano, esse longo cortejo de feridas amargas e sangrentas que tantas vezes nos cabe curar ou alliviar, em vão buscariamos nos doutos tratados dos escriptores, ou nos annaes da jurisprudencia.

$E^{\prime}$ que semelhante trabalho de psychologia pratica se realisa no asylo discreto e confidente de nosso gabinete; alli, é que taes espectaculos e taes ensinamentos se desenvolvem, alli é que o homem se mostra sob os mais varios e oppostos aspectos, rico ou pobre, culpado ou innocente, oppressor ou opprimido; alli, ora se nos exhibem cruas e inacreditaveis ignominias e baixezas, filhas ferozes do odio e da vingança, - ora se nos apresentam, impondo-se ao nosso respeito, lances de abnegação que a sociedade ignora, heroismos magnanimos de amôr e sacrificio; alli, emfim, todas as contradicções, todas as galhardias indomitas do vicio e da virtude; e lutos e alegrias e confortos e anseios desesperados, e o direito em contraste com a força, a miseria com a riqueza, a desventura com a fortuna, a fraude com a honestidade.

Esses dramas da vida real, que ás vezes logram publicidade por via de julgamentos feitos perante a multidão ávida de emoções, mas que, quasi sempre, apenas se descobrem no recesso e confiança de nossos colloquios, não raro exce- 
dem, em paixão, originalidade, potencia e ardôr, a tudo quanto a ficção dos poemas, dos romances e do theatro, soube crear.

Imaginação não ha que não ceda ante a surpresa da realidade.

Nem ficção alguma existe, exactamente por ser tal, capaz de suscitar paixões tão ardentes, tão violentas emoções, quanto as torturas vivas e palpitantes que, não na imaginação, mas nos factos, perante nós fazem soluçar e delirar os nossos semelhantes"

E quando este contacto dramatico com a vida se consuma, começa, apenas, a tarefa do advogado.

Apenas começa e logo se lhe segue o estudo, que ha-de ser continuado, que ha-de durar tanto quanto dura a propria vida.

"Ai do advogado, escreveu Henri Robert, que seduzido pelos seus primeiros successos, confia, para acertar, apenas na sua facilidade de trabalho. Esse, não acertará. Si não trabalhar incessantemente, se incessantemente não enriquecer sua memoria, não formar seu estylo, não renovar sua cultura e seu espirito de observação, logo descerá á banalidade, á esterilidade intellectual."

Bem disse Zanardelli em uma de suas magistraes conferencias sobre a advocacia: - "una causa non é mai studiata abbastanza."

E tão bem o praticou o professor Morato, que sempre dedicou ao estudo, continuado, methodico, quotidiano, a parte melhor de seu tempo, por forma a se assenhorear de extraordinaria cultura.

Em Paris, durante nosso exilio, não alterou seu systema de vida e dedicou ao estudo o mesmo tempo e o mesmo horario de sempre, como se estivesse, não num aposento do Hotel Regina, da Cidade-Luz, mas em seu gabinete de trabalho, em São Paulo.

Nas horas vagas, visitava commigo a Faculdade de Direito de Paris, a nos confortar, ambos, da saudade que sentia- 
mos desta nossa Casa, ou então, a sós, percorria as livrarias, á procura de um rebelde diccionario latino, que não havia meio de se descobrir.

Senhor absoluto das letras juridicas, conhecedor profundo do vernaculo, valia a pena vel-o manejar o florete na luta forense.

$\mathrm{Si}$, ás vezes, tinha assômos de indignação e revolta ante a injustiça, muitas outras vezes brilhantemente a fustigava em elegantissimos lances de esgrima - lances que faziam o desespero de seus adversarios, apanhados em fraquezas ou cincadas.

Não se preoccupem os leigos que me ouvem.

Nós, advogados, falamos em florete, em espada e outros perigosos instrumentos, em sentido apenas figurado.

Figurado mas igualmente. penetrante, por que a ironia fére mais fundo do que qualquer lamina.

De ha muito que usamos taes armas.

Conta-se que Cicero, em certo processo, precisou interrogar como testemunha um collega, não dos mais capazes, mas dos mais pretenciosos, por se dar ares, que mal lhe iam, de jurisconsulto. Irritado por ter de se sujeitar ao interrogatorio de Cicero, de quem não era amigo, apenas este lhe perguntou o que sabia sobre o caso em debate, respondeu asperamente:

- Não sei nada.

- Perdão, replicou Cicero, não o estou interrogando sobre materia de direito e sim sobre materia de facto.

Aliás, nesse sentido e a esse tempo, não faltava ao professor Morato boa companhia: - ao seu lado trabalhava o saudoso Estevam de Almeida, que sabia ser férino, quando preciso.

Carta feita, copiava eu a machina um arrazoado do dr. Estevam, e, em um topico, li que o adversario, em dada questão de direito, havia "mettido os pés pelos pés" 
Pedi innocentemente ao Mestre que me esclarecesse:

- O Senhor não quiz dizer, como é usual, "metter as pés pelas mãos"? - perguntei.

- Quem é nosso adversario? - indagou elle por sua vez.

- E' o dr. Fulano de tal.

- Ah! Então o original está certo. Mantenha o "metter os pés pelos pés". Esse nosso adversario não tem mãos.

Só tinha pés...

E por conta do professor Morato vá a irritação de certo rabula sempre que se defrontavam em algum processo. Ás heresias e rabulices do adversario, o professor Morato acudia, elegantemente, com uma apropositada fabula de Lafontaine. 0 rabula, que tanto não conhecia a fabula quianto não entendia francez, mas que, por instincto, sentia roçar e penetrar em suas carnes o golpe de florete, expandia-se com mal reprimida revolta, contra esse "tal senhor Lafontaine de que tanto gosta o dr. Morato"

Durante muitos annos o professor Morato exerceu a presidencia do Instituto da Ordem dos Advogados.

Foi, para essa instituição, um de seus periodos mais brilhantes.

Afim de incrementar o estudo das questões juridicas, o então presidente empenhava-se pessoalmente junto aos collegas para que apresentassem theses ao debate, relatando-as e provocando, assim, a inscripção de outros oradores.

Elle proprio, ora iniciava os debates, ora tomava parte nas discussões, com a capacidade e elevação que todos the reconhecem.

Formou-se, assim uma brilhante collectanea de estudos juridicos, publicados periodicamente na Revista dos Tribunaes, mas dignos de ser reunidos em volume.

Ao professor Morato tambem se deve o Codigo da Ethica Profissional approvado pelo Instituto, que mais tarde 
serviu de base para a elaboração do Codigo adoptado no Rio de Janeiro, pela instituição congenere.

A elle ainda ha-de ser imputada a bôa politica de convivio intellectual dos advogados com os juizes, nas sessões do instituto, e, mais, uma longa e paciente obra de assistencia aos collegas.

Com particular destaque, lembro sua actuação formando e dirigindo um quadro de defensores para os revolucionarios de 1924, quando era temeridade fazer-se ouvir a voz da defesa no tribunal improvisado no proprio carcere, que outra coisa não era se não uma praça de guerra.

Foi realmente notavel e brilhante sua direcção no Instituto.

Falem por mim, com mais eloquencia, os annaes da época.

Sua producção juridica, apesar de esparsa, é vasta e consta de innumeros pareceres, artigos de doutrina, discursos, conferencias e monographias, entre as quaes as suas duas dissertações de concurso.

Muito se empenhou para a adopção da oralidade em nosso processo civel e no recente Congresso de Direito Judiciario, que, como Ministro de Estado, tive a honra de presidir, o professor Morato pronunciou notaveis discursos em defesa de seu ponto de vista, logrando convencer a assistencia, formada, que era, por juizes vindos de todos os Estados.

Ainda um trabalho notavel a destacar: - seu laudo e todo o seu concurso feliz e brilhante na solução do litigio entre São Paulo e Minas, relativamente aos limites entre os dois Estados.

Celebres "mercuriales des gens du roi", do seculo XVI, aconselhavam fallassem os advogados "sincerement, brièvement et élegament" - "ut vere, breve et ornata dicant". 
Essas tres palavras ainda são verdadeiras, diz Henri RoBErT, que accrescenta: "hoje ainda, não se poderia definir por forma mais justa, nem mais concisa, o ideal de uma bôa defęsa".

A inteira vida de jurista e de homem publico do professor Morato revela a pratica constante dessas tres virtudes.

Advogado, professor, parlameintar, sua força de convicção foi e é poderosa, porque sempre falou "sincerement, brièvement et élégament"

Sinceramente, eis que jamais patrocinou, no pretorio ou na tribuna publica, qualquer causa, sem a adhesão prévia de sua consciencia:

"l'accento che maggiormente puó persuadere, disse muito bem ZANARDELLI, é l'accento dell'onestá"

Mas esse tom não se cria por artificios. Para vencer, ha-de resultar de uma convicção intima, e sincera: "qui veut convaincre, doit être convaincu d'abord", tambem escreveu Clemenceau, dizendo, "o orador prende o auditorio menos pela qualidade positiva de seus argumentos, reservados ao prazer dọs que hão de commental-os, do que pela sensação da somma de si mesmo que empenha no combate"

Assim Berryer poude vencer perante os convencionaes, em França, quando exclamou "eu trago perante a convenção a verdade e minha cabeça. Podereis dispôr de uma, depois de ter ouvido a outra"

Brevemente sempre pleiteou o Mestre, que hoje homenageamos, fugindo da oratoria romantica, vasia e palavrosa. Suas peças oratorias são todas peças logicas de persuação e raciocinio.

Pensa o publico com frequencia, diz um illustre jurista francez, que um grande advogado ha-de ser, por força, "grandiloquente e tumultuoso"

Engano: "il faut que seul, le feu de la conviction vuus anime, que le but à atteindre soit l'object de tous vos efforts. 
Il faut enfin consentir ài s'oublier soi-même, pour ne penser qu'a la cause et au resultat à obtenir"

"Il faux vouloir convaincre et non seduire."

Elegantemente tambem falou e escreveu sempre nosso mestre, manejando com superioridade e destreza o vernaculo, em phrases incisivas, sim, mas lapidares, harmoniosas e cheias de vida.

Digam-n'o os estudantes, que sempre accorreram ás suas aulas.

Fallem os annaes do parlamento, que attestam o exito de seus discursos.

Deponham todos quantos manuseiam e citam os seus trabalhos, modelarmente redigidos.

Disse, de inicio, que o exito moral e intellectual do professor Morato era e é devido á sua formação de jurista, de sacerdote do direito.

Mas disse pouco.

Essa formação é um todo, é um complexo, que, para finalizar este estudo, vou decompor em seus elementos fundamentaes.

Faço-o, porque estou empenhado em apresentar e fixar sua personalidade-typo, sua personalidade-modelo.

Esses elementos fundamentaes são os seguintes:

- a par de um caráter sem jaça, uma capacidade intelectual invulgar. $E$, dahi, sua cultura juridica, que é realmente notavel, por que alicerçada em solidos conhecimentos philosophicos e em profundo conhecimento do vernaculo.

Tal é, meus collegas e meus senhores, o mestre a quem hoje conferimos o titulo de professor emerito da Faculdade de Direito de São Paulo.

Professor Francisco Morato, conferindo-lhe o titulo que com toda a justiça lhe con- 


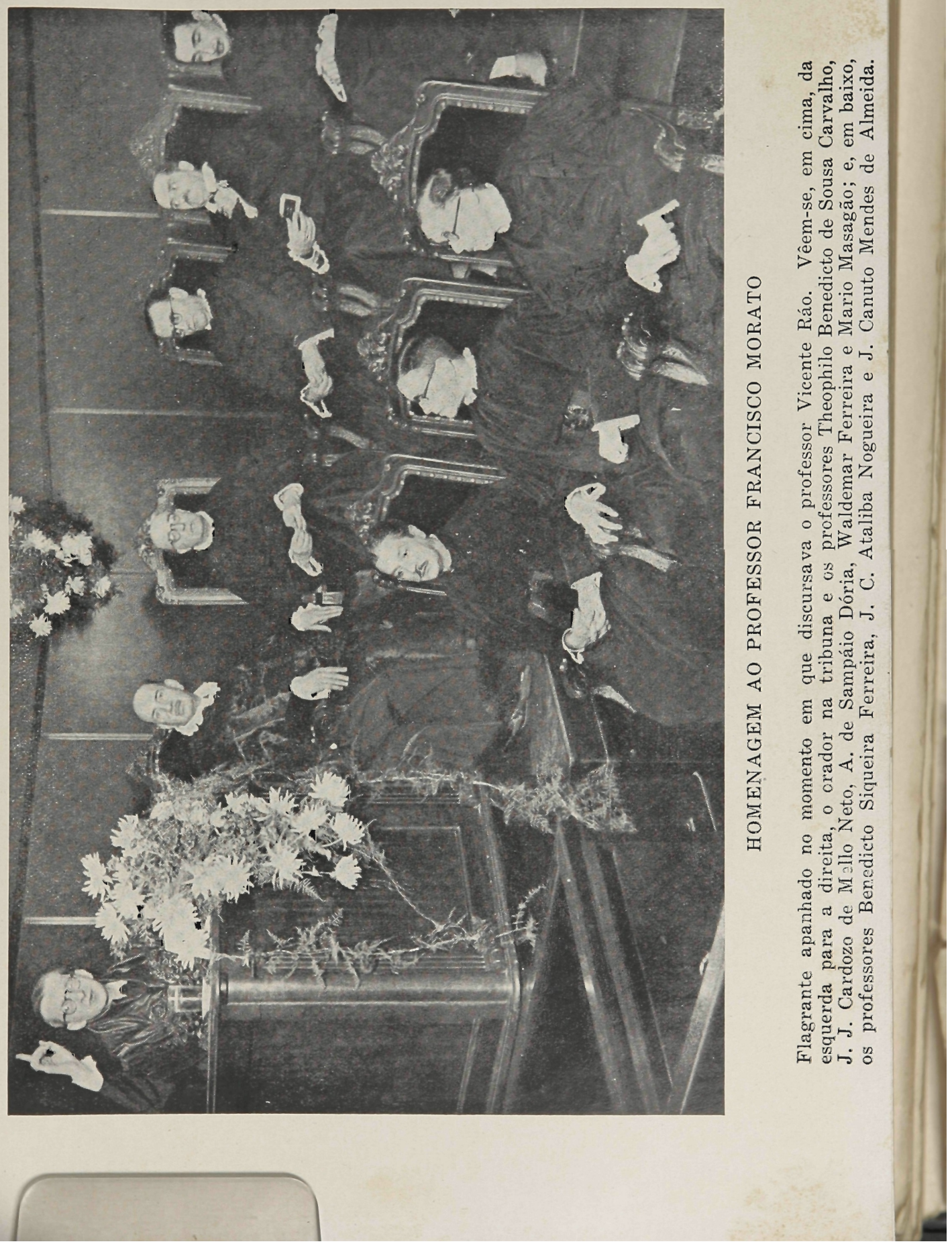


fere, a Congregação, aqui reunida, não quer dar ao seu gesto o sentido de uma despedida. Não, não o quer. Não o quer, porque a intenção que animou os professores, outra e mais elevada foi, tal a de proclamal-o mestre entre os mestres, guia e inspirador nosso, que nesta casa sempre será havido por presente, por seu talento, por suas virtudes, por seus anseios, por suas realisações.

Não, não é de despedida esta festa. Não o é, porque ainda esperamos muito e muito de sua collaboração, por que de si muito aguardamos.

E' esperança nossa, emerito professor Morato, termos em nossa bibliotheca, em breve, a enriquecer e honrar nossas letras juridicas, o seu curso de Direito Judiciario, que virá perpetuar suas magistraes preleções, proferidas nesta Casa.

E' desejo nosso, é graça que lhe rogamos, que mantenha sem interrupção alguma seu contacto com a Faculdade.

$E^{\prime}$ voto, que ardentemente fazemos, o de que Deus lhe prolongue por muitos e muitos annos a vida, que tão util tem sido aos seus collegas, aos seus discipulos, aos seus concidadãos, á sua e nossa Patria. 